\title{
Reinforcement and Restoration Studies of the Edremit Ataturk House
}

\author{
M. Bilal Bagbanci \\ Faculty of Architecture \\ Bursa Uludag University \\ Gorukle-Bursa, Turkey \\ bilalbagbanci@yahoo.com
}

\begin{abstract}
Edremit Ataturk House has been restored under the international restoration principles. Due to its importance, a systematic study was carried out to prevent the building from suffering damage. The current situation of the building was investigated by using slightly destructive and non-destructive test methods. Flat-jack and shear tests were used in order to identify the mechanical properties of masonry walls according to the ASTM standards. The operational modal analysis test method was used in order to understand its dynamic characteristics. After the diagnosis phase, a finite element model was prepared and calibrated according to the in-situ test results. The reinforcement studies were performed according to the finite element modal analysis results. Finally, the differences between the dynamic properties of the structure were evaluated by vibration tests before and after the restoration works.
\end{abstract}

Keywords-masonry; NDT methods; operational modal analysis; restoration

\section{INTRODUCTION}

Edremit is one of the districts of Balikesir Province which is located in the north-western Turkey, on the coast of the Aegean Sea. The studied building is located in the district center and was constructed in the first quarter of the 20th century. The building is a modern architectural heritage and is considered valuable under many aspects [1]. The house gained its importance with the hosting of Mustafa Kemal Ataturk, the founder of the Republic of Turkey, in 1934. Today's legal codes and standards are not sufficient for the preservation, diagnosis, analysis, and strengthening of such historical buildings. The most important reason for this is that each structure has its own characteristics. The analysis of historical buildings has important problems due to the lack of information about the complexity of their geometry, the diversity of material properties, the construction techniques and the damages that occurred during the buildings' lifetime. For this reason, the restoration problems of the building were evaluated within the scope of the Venice Charter of 1964 and the recommendations of ICOMOS/Scientific Committee on Analysis and Restoration of International Architectural Heritage Buildings (ISCARSAH, 2001) [2, 3]. The Venice Charter and ICOMOS recommendations have the basic concepts of restoration, the rules and the methodology that was followed for the restoration of the building.
Restoration studies should be organized and analyzed in steps in a multidisciplinary study. No action should be taken without understanding the benefits or harms that could happen to architectural heritage monuments. It is important to fully understand the structural behavior and material properties before the restoration. Conservation and restoration problems can only be dealt with successfully when the building is carefully diagnosed [4]. The interior and exterior walls were constructed with the use of solid brick and lime mortar as a binding material. Masonry brick structures are sensitive against lateral loads. Failures can occur if the induced tensile forces exceed the maximum tensile stress [5]. For that reason, horizontal beams or slabs between the walls and the wall-roof connections are very important. Experimental studies are needed in order to find the material properties and the dynamic behavior of structures [6]. Finite element analysis is also important in order to identify the structural behavior of a structure. Finally, decisions must be taken for the reinforcement of the structure.

In this study, flatjack and shear tests were applied in order to find mechanical properties such as compressive stress, shear stress and elastic moduli of the masonry walls. In-situ vibration tests were conducted to identify the dynamic properties of the structure. The mode shapes and natural frequencies of the structure were investigated by Operational Modal Analysis (OMA) test method. A finite element model of the structure was prepared and calibrations were done according to the test results. After the reinforcement and restoration of the structure, in-situ vibration tests were performed again in order to understand the changes in the dynamic characteristics and compare the results with the first vibration tests' results.

\section{ARCHITECTURAL FEATURES AND CONSTRUCTION TECHNIQUES}

The architect of the house is unknown. Located in the center of the district, the house consists of three stories, basement, first and second floor. The plan and facade arrangements of the structure reflect the Izmir Levantine residences. The building suffered two major fires, in 1946 and in 1991. As a result of the fire in 1991, the roof of the house and all timber elements collapsed and only the masonry walls and reinforcement concrete slabs survived. After the fire, the house lost its function and could not be used for many years. 
The building's approximate dimensions are $14 \mathrm{~m} \times 10 \mathrm{~m}$. All exterior and interior walls were built with solid bricks and lime mortar as a binding material. Solid brick dimensions are $5.5 \mathrm{~cm} \times 11 \mathrm{~cm} \times 24 \mathrm{~cm}$. The basement floor was used as storage. The living spaces (sofa, rooms, kitchen, toilet and bath) were in the first and second floor. The basement floor height is $2.10 \mathrm{~m}$, while the first and second floor heights are $3.50 \mathrm{~m}$. The outer walls are $50 \mathrm{~cm}$ thick. The interior walls were $45 \mathrm{~cm}$ in the basement, $30 \mathrm{~cm}$ in the first floor and $25 \mathrm{~cm}$ in the second floor. The walls were plastered with lime mortar. The section of timber beams were $6 \times 15,6 \times 10$, and $6 \times 12 \mathrm{~cm}$. The slabs of the wet spaces were arranged as reinforced concrete. Reinforced concrete slabs are formed on the masonry walls in this type of construction [7]. Only the slab in the entrance part of the building is different from the other Reinforced Concrete (RC) slabs. In this part, the RC slabs were supported by IPN140 beams. Timber and RC slabs on the first-floor plan view can be seen in Figure 1. The timber floor and RC slabs were constructed at the same time because there are no construction joints at the intersection of the walls, and the floor elevations are equal. Despite the fire, the RC slabs are intact today. The $\mathrm{RC}$ slabs and the timber beams used in the construction of the building are shown in Figure 2. The detail of the RC slab in the entrance of the building which is supported by IPN140 beams can be seen in Figure 3.

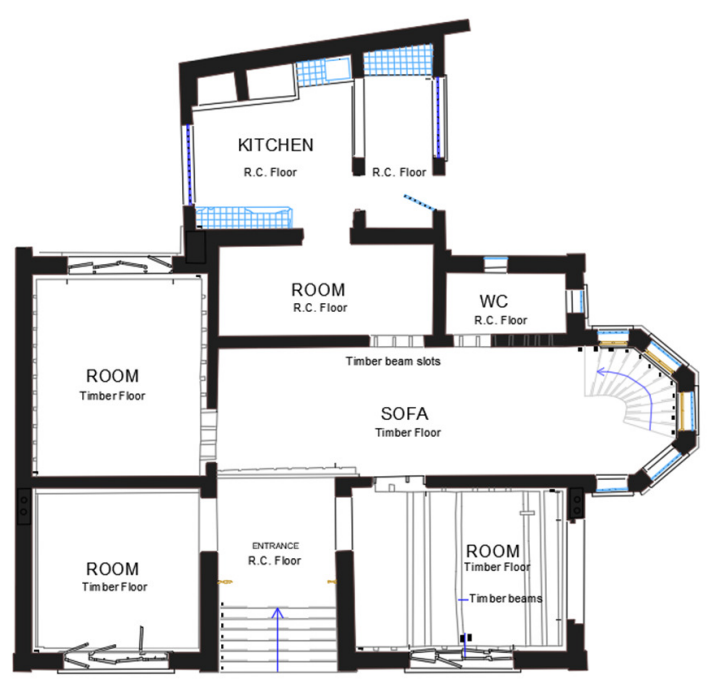

Fig. 1. The first floor plan view

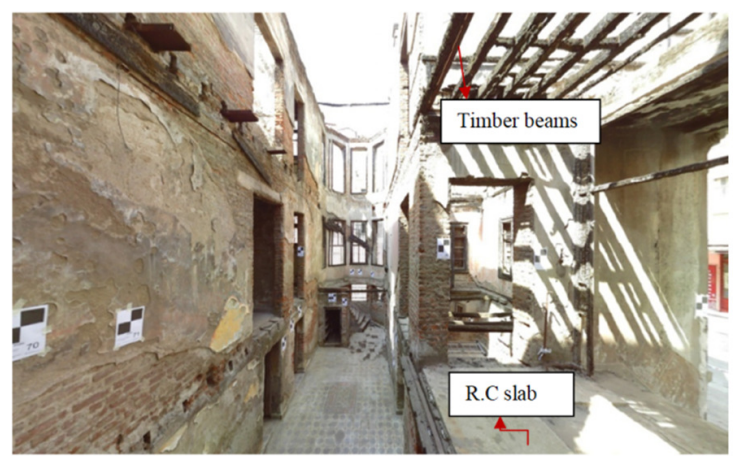

Fig. 2. An inside view of the house

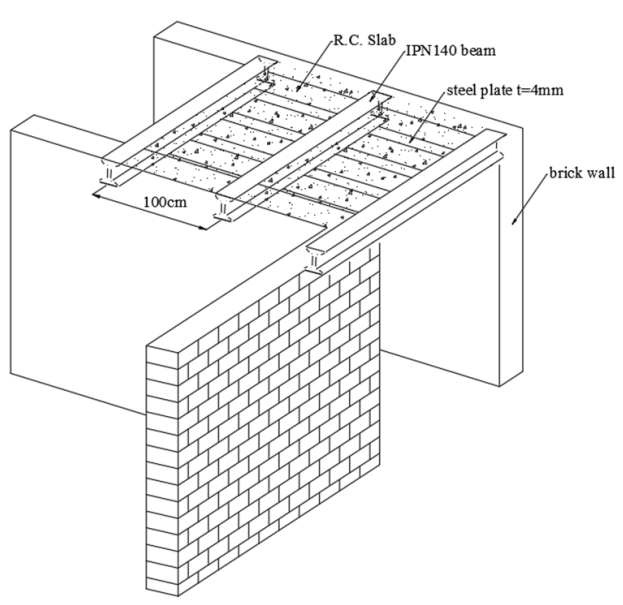

Fig. 3. The detail of the RC slab in the entrance of the building

\section{MATERIAL PROPERTIES AND VIBRATION TESTS}

Physical and mechanical properties were investigated by laboratory and in-situ tests. Compressive stress, shear stress, and elastic moduli of walls were identified by using flat-jack and shear test methods. A double layered thin plate called as flat-jack was inserted in a cut slot of the mortar. Hydraulic oil pressure was inflated into the flat-jack and displacements were continuously monitored (Figure 4(a)). The tests were performed and calculations were done according to ASTM C1197 and ASTM C1314 [8,9]. In shear test, the flat-jack is horizontally inserted at one end of the test unit and the oil pressure was inflated into the flat-jack until the slip of the mortar (Figure 4(b)). Method C was performed in shear test according to ASTM C1531-09 [10].

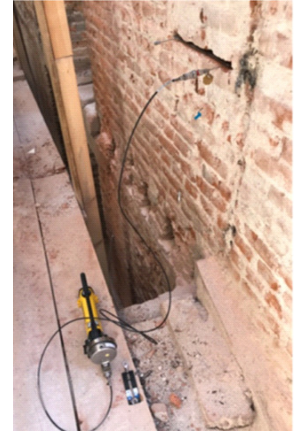

(a)

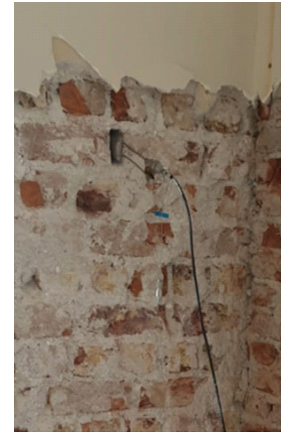

(b)
Fig. 4. Mechanical tests: a) Flat-jack test, b) shear test

The calculation of compressive stress, elastic moduli and shear stress are presented below.

Compressive stress:

$$
f_{m}=K_{m} \cdot K_{a} \cdot p
$$

where $K_{m}$ is a dimensionless constant related to the stiffness and geometrical properties of the flat-jack, $K_{a}$ is the ratio of the area of the flat-jack to the area of the slot and $p$ is the flat-jack pressure, psi or $\mathrm{MPa}$.

The chord modulus at any point $i$ : 


$$
E_{s i}=\frac{f_{m i}}{\varepsilon_{m i}}
$$

where $f_{m i}$ is the stress at point $i$, and $\varepsilon_{m i}$ is the strain at point $i$ [8]. The elastic moduli of the composite walls were calculated using end points of 0.05 and 0.33 chord moduli of elasticity values [9].

The calculation of average bed joint shear stress:

Horizontal force:

$$
P_{h}=K_{m} \cdot A_{f} \cdot p
$$

where $K_{m}$ is a dimensionless constant related to the stiffness and geometrical properties of the flat-jack, $A_{f}$ is the area of the flat-jack and $p$ is the flat-jack pressure at crack initiation or slip.

Shear stress:

$$
\tau=\frac{P_{h}}{A_{j}}
$$

where $P_{h}$ is the maximum force applied by the hidrolic pomp and $A_{j}$ is the gross area of upper and lower bed joints [10]. Density and specific gravity were calculated by using standard test methods [11]. The physical and mechanical properties used in the construction of the walls are presented in Table I.

TABLE I. BRICK WALL MECHANICAL AND PHYSICAL PROPERTIES

\begin{tabular}{|c|c|}
\hline Compressive stress $\left(\mathrm{N} / \mathrm{mm}^{2}\right)$ & 2.1 \\
\hline Shear stress $\left(\mathrm{N} / \mathrm{mm}^{2}\right)$ & 0.50 \\
\hline Modulus of elasticity $\left(\mathrm{N} / \mathrm{mm}^{2}\right)$ & 2750 \\
\hline Shear modulus $\left(\mathrm{N} / \mathrm{mm}^{2}\right)$ & 1282 \\
\hline Poisson's ratio & 0.17 \\
\hline Unit weight $\left(\mathrm{kN} / \mathrm{m}^{3}\right)$ & 18 \\
\hline
\end{tabular}

The Operational Modal Analysis (OMA) test method was used to determine the dynamic characteristics of the structure. The mode shapes and natural frequencies of the structure were found by this non-destructive test method by placing high sensitivity accelerometers on the walls of the structure. In this technique only the responses of the structure are measured, so this method is also called output-only modal analysis.

The modal parameters were determined by the Frequency Domain Decomposition Technique (Peak-Picking Technique). The relationship between the input $x(t)$ and output $y(t)$ can be written as $[12,13]$ :

$$
[\operatorname{Gyy}(w)]=[H(w)]^{*}[G x x(w)][H(w)]^{T}
$$

where $G x x$ is the Power Spectral Density (PSD) matrix of the input, Gyy is the PSD matrix of the output, $H$ is the Frequency Response Function (FRF) matrix, and ${ }^{*}$ and ${ }^{\mathrm{T}}$ denote complex conjugations and transpositions respectively. The output PSD can be reduced to a pole/residue form as follows:

$$
[G y y(w)]=\sum_{k=1}^{m}\left(\frac{\left[A_{k}\right]}{j w-\lambda k}+\frac{\left[A_{k}\right]^{*}}{j w-\lambda k^{*}}+\frac{\left[B_{k}\right]}{-j w-\lambda k}+\frac{\left[B_{k}\right]^{*}}{-j w-\lambda k^{*}}\right)
$$

where $A_{k}$ is the $k$-th residue matrix of the output PSD. The response spectral density matrix can be written in the form below, considering a lightly damped system [12]:

$$
[G y y(w)]=\sum_{k=S u b(w)}\left(\frac{d k \psi k \psi k^{T}}{j w-\lambda k}+\frac{d k^{*} \psi k^{*} \psi k^{T}}{j w-\lambda k^{*}}\right)
$$

where $d k$ is a scalar constant and $\psi k$ is the $k$-th mode shape vector. Thus, by performing singular value decomposition of the output PSD matrix at discrete frequencies $w=w_{i}$, the following can be obtained:

$$
\left[\widehat{G} y y\left(j w_{i}\right)\right]=U_{i} S_{i} U_{i}^{H}
$$

where matrix $U_{i}$ is a unitary matrix holding the singular vector $u_{i j}$ and $S_{i}$ is a diagonal matrix holding the scalar singular values $s_{i j}$; the superscript ${ }^{\mathrm{H}}$ denotes complex conjugation and transposition. Near the peak corresponding to the $k$-th mode in the spectrum, only the $k$-th mode is dominant, and the PSD matrix approximates to a rank-one matrix as [13]:

$$
\hat{G} y y\left(j w_{i}\right)=s_{i} u_{i 1} u_{i 1}^{H}, \quad w_{i} \rightarrow w_{k}
$$

The first singular vector at the $r$-th resonance is an estimate of the $r$-th mode shape [13]:

$$
\hat{\phi} r=u_{r 1}
$$

The PSD matrix rank is equal to the multiplicity number of the modes in case of repeated modes. The modal frequencies can be calculated by the peaks of the singular value plots. The corresponding singular vectors give the mode shapes. [13]. Testbox 2010 series data acquisition system was used [14]. Six monoaxial accelerometers were placed at the first and second floor of the building for the test. The orientation of sensors was carefully checked to ensure they were perpendicular to each other. The placement of the sensors in perspective view and plan view are seen in Figure 5. The singular values of the spectral densities of all the test setup are shown in Figure 6.
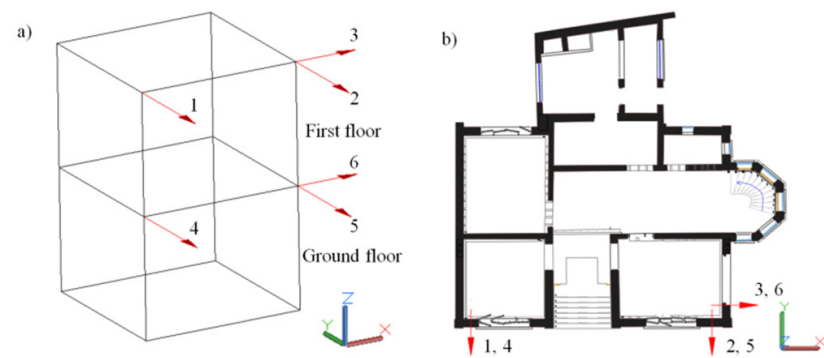

Fig. 5. The placement of sensors: a) perspective view, b) plan view

\section{FINITE ELEMENT MODAL ANALYSIS}

Finite element analysis was performed with Algor V20 finite element analysis program [15]. The solid elements were three-dimensional and generally 8 -noded brick type with three degrees-of-freedom at every node. The material properties of the brick walls were obtained from the test results. In the finite element mesh, 15964 solid elements were used. Natural frequencies, mode shapes and mass participation factors were obtained from the modal analysis. The natural frequencies obtained from modal analysis were compared with the in-situ vibration test results and the calibrations were made until the errors were less than $10 \%$. After the calibrations, the elastic moduli of the walls were taken with an average of $2250 \mathrm{~N} / \mathrm{mm}^{2}$ with an $18 \%$ error between the flat-jack test results. The reason for this is the small number of field tests. More accurate results will be achieved as the number of tests increases. The first four mode shapes and the frequencies are presented in Figure 7. 


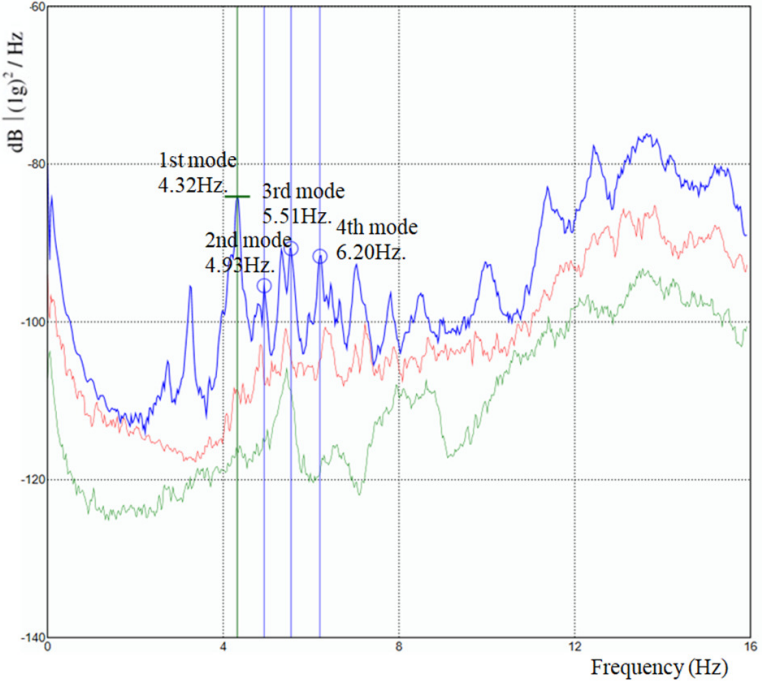

Fig. 6. The singular values of the spectral densities

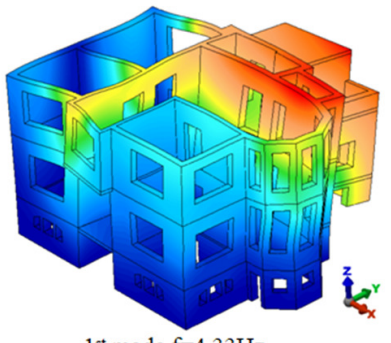

$1^{\text {st }}$ mode $\mathrm{f}=4.33 \mathrm{~Hz}$

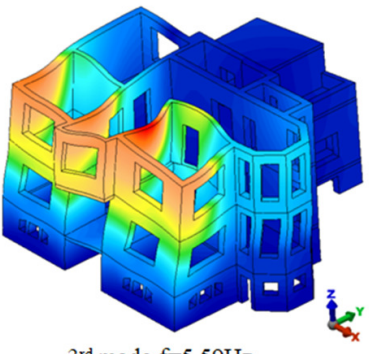

$3^{\text {rd }}$ mode $\mathrm{f}=5.59 \mathrm{~Hz}$.

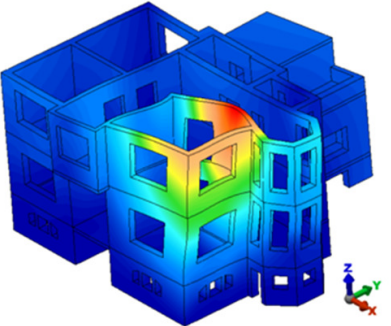

$2^{\text {nd }}$ mode $\mathrm{f}=4.73 \mathrm{~Hz}$.

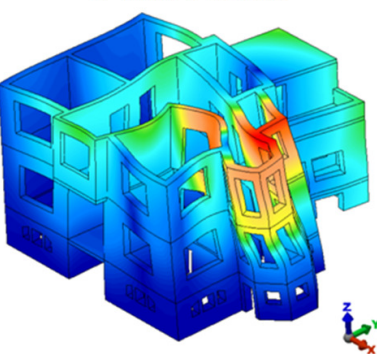

$4^{\text {th }}$ mode $\mathrm{f}=5.86 \mathrm{~Hz}$
Fig. 7. The first four mode shapes and frequencies: $1^{\text {st }}$ mode: displacement in y direction, $2^{\text {nd }}$ mode: torsion, $3^{\text {rd }}$ mode: displacement in $\mathrm{x}$ direction and $4^{\text {th }}$ mode: torsion

The first four mode frequencies obtained from modal analysis and the vibration tests were compared with each other. The error between them ranged in $0.23 \%-5.48 \%$ as shown in Table II. It can be stated that the finite element model represents the real behavior of the structure after the calibrations.

TABLE II. FIRST FOUR MODE FREQUENCIES OBTAINED FROM VIBRATION TESTS AND FINITE ELEMENT MODAL ANALYSIS

\begin{tabular}{|c|c|c|c|}
\hline Mode number & Vibration test & Finite element & Error (\%) \\
\hline 1 & 4.32 & 4.33 & 0.23 \\
\hline 2 & 4.93 & 4.73 & 4 \\
\hline 3 & 5.51 & 5.59 & 1.43 \\
\hline 4 & 6.20 & 5.86 & 5.48 \\
\hline
\end{tabular}

The total mass participation factor of the first four modes was $15.28 \%$ in $\mathrm{x}$ direction and $33.27 \%$ in y direction. These ratios are low because of the absence of the timber beams and the roof of the house.

\section{REINFORCEMENT STUDY}

Out-of-plane movements were observed on the first and second floor walls according to the mode shapes of the building. There were no out-of-plane movements observed on the walls constructed with reinforcement concrete slabs except the roofless walls. After the restoration works, the construction of the timber floors and the roof system reduced these movements to some extent. However, timber slabs cannot provide as much rigidity as reinforced concrete floors. Therefore, before the timber slab constructions, the walls were strengthened in order to reduce the out-of-plane movements of the first and second story walls. In the reinforcement of the walls a textile product with an appropriate bonding plaster was used. The reinforcement of the walls and the textile product can be seen in Figure 8.

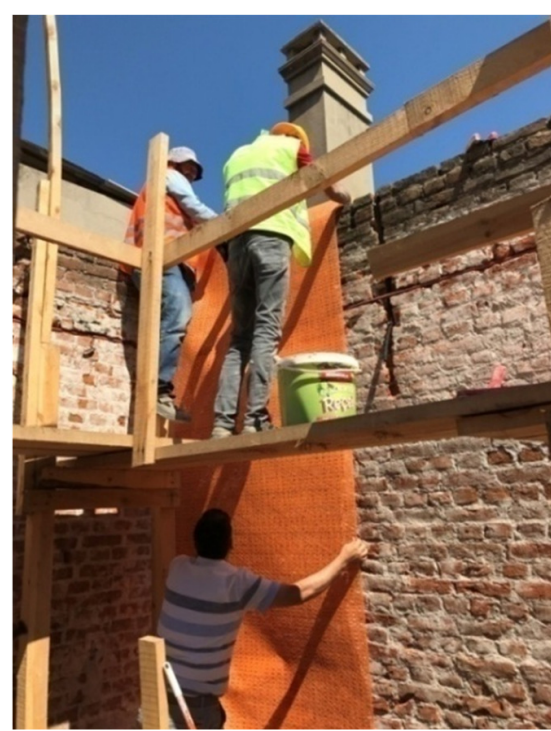

Fig. 8. The reinforcement of brick walls

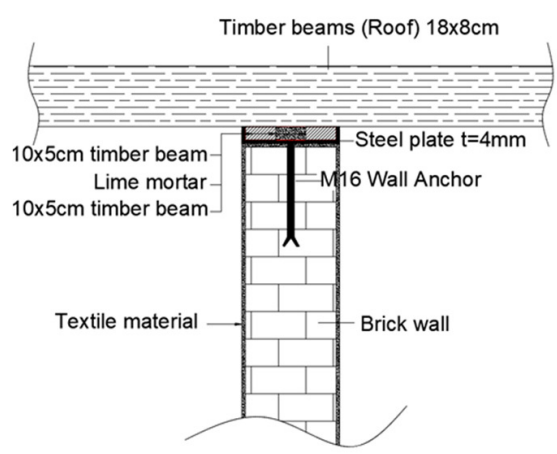

Fig. 9. Details of the timber beams on top of the walls

After the reinforcement of the walls, timber beams were prepared on the walls before the roof construction. They were 
supported on top of the walls by steel plates with anchorage (Figure 9). In Figure 10 we can see the timber beams arranged on the top of the walls. The roof of the house was finished after the reinforcement of the brick walls.

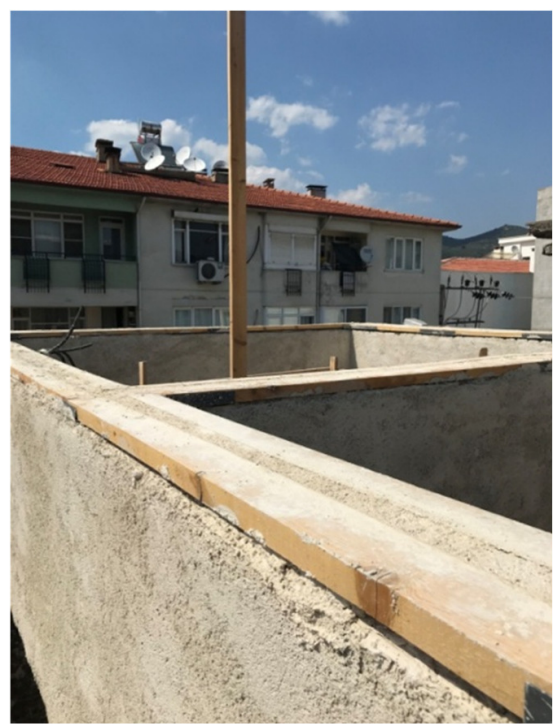

Fig. 10. The timber beams arranged on the top of the walls

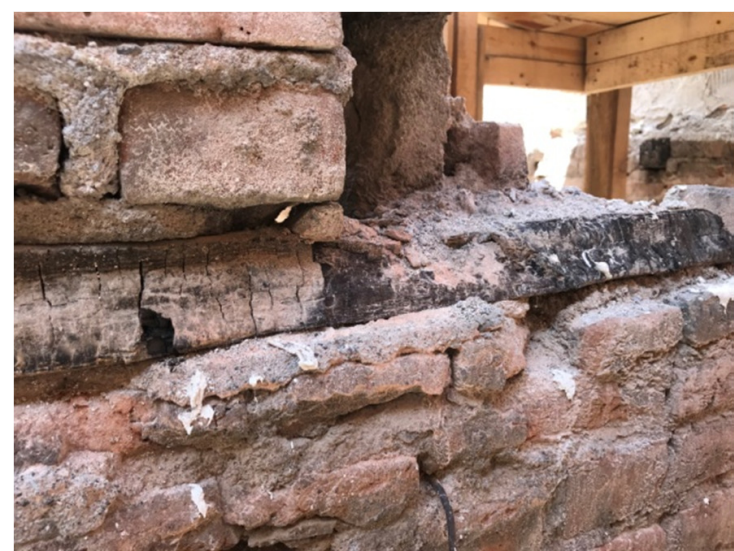

Fig. 11. A timber beam which was burned in 1991

The timber beams were arranged between the first and second floor walls (Figures 11-12). Local deteriorations occurred under the RC slab which was located in the entrance of the building. The IPN140 beams and metal plates between the RC slabs were corroded. Grout was used under the RC slab for the deteriorations. The IPN beams and the metal plates were protected against corrosion by using anticorrosion paint (Figure 13). After the reinforcement and the restoration of the house, in-situ vibration tests were performed again. The sensor placements were the same with the previous tests which were performed before the restoration studies. The values of the spectral densities of the test are shown in Figure 14. These values show us that the frequencies of the house changed. The first frequency of the house was increased by $15 \%$ due to the completion of the timber beams and the roof of the house.

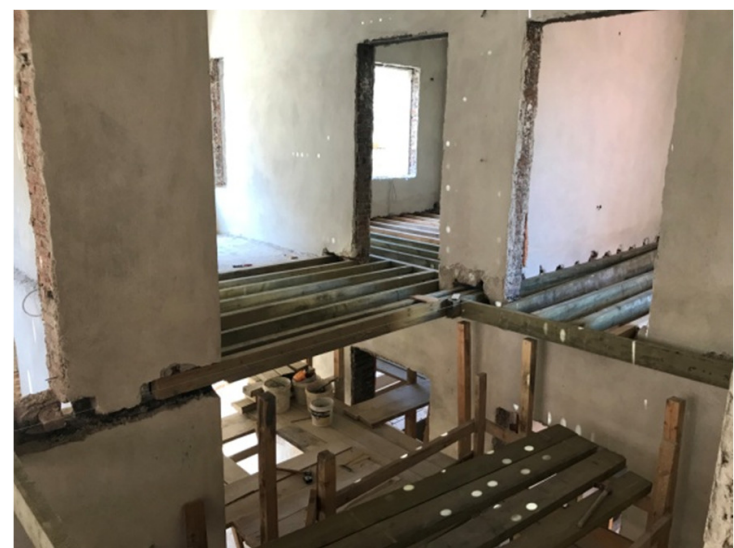

Fig. 12. Timber beams arranged between the walls

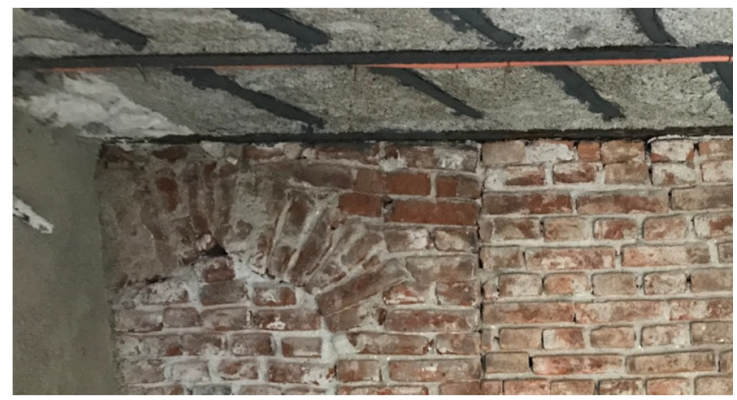

Fig. 13. The reinforcement of the R.C slab in the entrance of the building

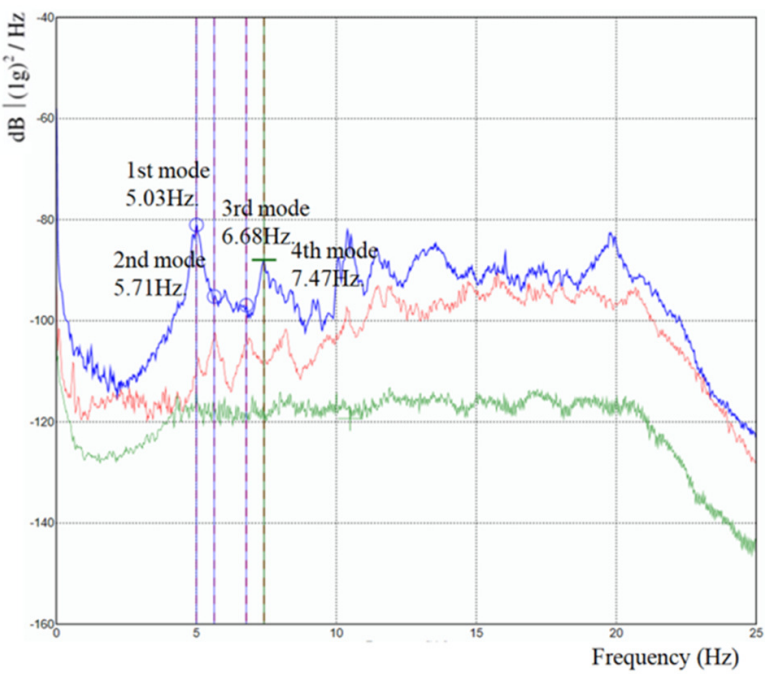

Fig. 14. Singular values of the spectral densities (after restoration)

\section{CONCLUSIONS}

In order to conduct a correct restoration of a historical building, all diagnostic studies related to the building should be performed. The restoration works must be carried out within the framework of conservation, repairment, and strengthening principles. In this study, the dynamic identification and the reinforcement study of the Edremit Ataturk House were investigated by using experimental tests and finite element analysis. The results are: 
- Flat-jack, shear, and vibration tests are important for the accurate description of material properties and dynamic characteristics.

- Finite element analysis calibrated by test results represents the real behavior of the structure accurately.

- The first frequency of the house increased by $15 \%$ after the reinforcement and restoration. The completion of the timber beams between the walls and the finishing of the roof of the house caused an increase in frequency.

- After the calibration of the finite element model, the differences between the vibration test results and finite element modal analysis ranged with a maximum of $5.48 \%$.

- The mass participation ratio of the house increased after the restoration.

\section{ACKNOWLEDGMENT}

The author of this paper worked as a consultant civil engineer in the restoration of the Edremit Ataturk House.

\section{REFERENCES}

[1] B. M. Feilden, J. Jokilehto, Management guidelines for world cultural heritage sites, ICCROM, 1998

[2] ICOMOS, "International charter for the conservation and restoration of monuments and sites (the Venice Charter 1964)", 2nd International Congress of Architects and Technicians of Historic Monuments, Venice, 1964

[3] ICOMOS, Recommendations for the analysis, conservation and structural restoration of architectural heritage, ICOMOS, 2001

[4] L. Binda, "Investigation and diagnosis of historic materials", International Symposium Studies on Historical Heritage, Antalya, Turkey, September 17-21, 2007

[5] G. W. T. C. Kandamby, "Investigation and analysis of wall cracks in cement stabilized rammed earth technology", Engineering, Technology \& Applied Science Research, Vol. 9, No.4, pp. 4349-4354, 2019

[6] T. M. Shah, A. Kumar, S. N. R. Shah, A. A. Jhatial, M. H. Janwery, "Evaluation of the mechanical behavior of local brick masonry in Pakistan”, Engineering, Technology \& Applied Science Research, Vol. 9, No. 3, pp. 4298-4300, 2019

[7] H. I. Polat, "A classification study on the development stages of construction technologies in Turkey", Engineering, Technology \& Applied Science Research, Vol. 7, No.5, pp. 1909-1913, 2017

[8] ASTM, Standard C1197: Standard test method for in situ measurement of masonry deformability properties using the flatjack method, ASTM International, 2014

[9] ASTM Standard C1314: Standard test method for compressive strength of masonry prisms, ASTM International, 2014

[10] ASTM Standard C1531: Standard test methods for in situ measurement of masonry mortar joint shear strength index, ASTM International, 2016

[11] TS 699: Methods of testing for natural building stones, Turkish Standard Institute, 2009

[12] J. S. Bendat, A. G. Piersol, Random data: Anaysis and mesurement procedures, Wiley, 1986

[13] C. Raineri, G. Fabbrocino, E. Cosenza, G. Manfredi, "Implementation of OMA procedures using Labview: Theory and application", 2nd International Operational Modal Analyses Conference, Copenhagen, Denmark, April 30-May 2, 2007

[14] http://www.tdg.com.tr/en/urun/8/testbox 2010

[15] Algor V20.00, Algor Inc, 2007

\section{AUTHORS PROFILE}

M. Bilal Bagbanci is a civil engineer and has been working as an instructer in Uludag University Architectural Faculty since 2002. His research areas are: Finite element analysis, NDT methods, operational modal analysis, the structural analysis of timber and masonry structures. 